Article

\title{
Tensile Behavior and Deformation Mechanism of Fe-Mn-Al-C Low Density Steel with High Strength and High Plasticity
}

\author{
Jingyu Pang ${ }^{1,2}$, Zhanming Zhou ${ }^{1}$, Zhengzhi Zhao ${ }^{1,2, *} \mathbb{C}$, Di Tang ${ }^{1,2}$, Juhua Liang ${ }^{1}$ and \\ Qing $\mathrm{He}^{1,2}$ \\ 1 Collaborative Innovation Center of Steel Technology, University of Science and Technology Beijing, Xueyuan \\ Road 30, Beijing 100083, China \\ 2 Beijing Laboratory for Modern Transportation Advanced Metal Materials and Processing Technology, \\ University of Science and Technology Beijing, Beijing 100083, China \\ * Correspondence: zhaozhzhi@ustb.edu.cn; Tel.: +86-10-6233-2617
}

Received: 23 July 2019; Accepted: 12 August 2019; Published: 16 August 2019

check for updates

\begin{abstract}
Tensile behavior and plastic deformation mechanisms of $\mathrm{Fe}-22.8 \mathrm{Mn}-8.48 \mathrm{Al}-0.86 \mathrm{C}$ low-density steel were studied in this thesis. After solution treatment $1100{ }^{\circ} \mathrm{C}$ for $1 \mathrm{~h}$; the steels obtained an excellent combination in mechanical properties; with tensile strength of $757.4 \mathrm{MPa}$ and total elongation of $68 \%$; which were attributed to the existence of annealing twins in austenite. The present steel presented a multiple stage strain hardening behavior which was associated with the changes of such dislocation substructures. With the increase of strain, the gradual transition from tangled dislocations to dense dislocation walls and microbands was found in (the transmission electron microscopy) TEM microstructures. Due to the influence of the evolution of the microstructure during the deformation process, the work hardening behavior of the experimental steel shows three distinct stages.
\end{abstract}

Keywords: low density steel; deformation; stacking fault energy; work hardening; microbands

\section{Introduction}

Automobile weight reduction is the direction of the development of modern automotive technology to meet the requirements of energy saving. Austenitic high-Mn(15-30 wt $\%) \mathrm{Fe}-\mathrm{Mn}-\mathrm{Al}-\mathrm{C}$ steels show particularly outstanding mechanical properties and are therefore highly promising candidates for such applications [1-4]. Due to their low cost and good mechanical properties, in the beginning these steels were developed in a search to replace $\mathrm{Cr}$-containing stainless steels. According to the chemical composition optimization, a higher content of aluminum was added to the high manganese steel. As a result, austenite Fe-Mn-Al-C steels have significantly reduced mass density (a 1.3\% reduction in density is obtained per $1 \mathrm{wt} \% \mathrm{Al}$ addition) and excellent strength-ductility balance due to alloying of $\mathrm{Al}$ and regained focus of researchers. $\mathrm{Al}$ is the most effective element in increasing the stacking fault energy (SFE) of austenite [5] and deformed microstructures exhibited the planar glide characteristics for high Mn-Al-C single phase steels.

According to the phase ingredient, Fe-Mn-Al-C steels can be classified as austenite, ferrite and duplex-based alloys. In austenitic Fe-Mn-Al-C steels containing high $\mathrm{Al}(5-12 \mathrm{wt} \%)$ and high $C(0.5-1.3 \mathrm{wt} \%)$, nanometer-scale ordered $\mathrm{k}$-carbides precipitates can be precipitated on face-centered-cubic (fcc) austenite during water quenching. The mechanical properties of Fe-Mn-Al-C steels can differ significantly, because of their chemical composition. For fully austenitic high Mn steels, stacking fault energy (SFE) is the main determinant of its deformation mechanism [6]. For fully 
austenitic high Mn steels, SFE is the main determinant of its deformation mechanism. The deformation mechanism of Fe-Mn-Al-C steel varies greatly with SFE. When the stacking fault energy is low, the deformation mechanism is transformation-induced plasticity (TRIP). With the increase of stacking fault energy, it gradually changes to twinning induced plasticity (TWIP) and to dislocation gliding [7]. The high density dislocation wall structures are considered as impenetrable barriers to the dislocation motion and further slip in the systems interacting with them leads to high strain hardening [8].

At present, little attention has been paid to the tensile behavior and microstructural evolution during plastic deformation of high Mn (20-25 wt\%) austenitic steels. The deformation mechanism of the steel is unclear. In the present investigation, a kind of high-strength plastic low-density steel (Fe-22.8Mn-8.48Al-0.86C) was developed by composition optimization. Tensile behavior and plastic deformation mechanisms of Fe22.8Mn-8.48Al-0.86C low-density steel were investigated in the present study based on SFE calculation, X-ray Diffraction (XRD), Optical Microscope (OM), Scanning Electron Microscope (SEM) and TEM at different deformation strains.

\section{Experimental}

A $20 \mathrm{~kg}$ ingot of experimental steel was prepared in a vacuum induction furnace. Chemical composition of the experimental steel is shown in Table 1 . The cast steel was heated to $1150^{\circ} \mathrm{C}$ for $1 \mathrm{~h}$, and then hot forged into a $40 \mathrm{~mm} \times 60 \mathrm{~mm} \times 80 \mathrm{~mm}$ billet. The billet was homogenized at $1200{ }^{\circ} \mathrm{C}$ for $1 \mathrm{~h}$, and hot rolled to the thickness of $5 \mathrm{~mm}$ with a reduction of $87.5 \%$ followed by water cooling to room temperature.

Table 1. Composition analysis of low-density steel (mass fraction, $\%$ ).

\begin{tabular}{cccc}
\hline Mn & Al & C & Fe \\
\hline 22.8 & 8.48 & 0.86 & Bal. \\
\hline
\end{tabular}

The steel plate was solution treated at $1100{ }^{\circ} \mathrm{C}$ for $1 \mathrm{~h}$ followed by water quenching to obtain stable austenite structure. For tensile tests, specimens with a gauge width of $12.5 \mathrm{~mm}$ and a gauge length of $50 \mathrm{~mm}$ were machined from the water quenched plate along the longitudinal direction. The tensile tests were conducted at temperature with a constant speed $(3 \mathrm{~mm} / \mathrm{min})$. Some tests were interrupted at different deformations $(10 \%, 30 \%$ and $68 \%$ based on Figure 2$)$ to observe the microstructures and the microstructural evolution.

The resulting microstructures were observed by OLS4100 (made by OLYMPUS, Tokyo, Japan) and Zeiss ULTRA 55-type (Oberkochen, Germany) field emission scanning electron microscopy (FE-SEM) after etching with $8 \%$ nital. Twin-jet polishing technique $\left(5 \%\right.$ perchlorate alcohol at $-30{ }^{\circ} \mathrm{C}$, applied potential of $50 \mathrm{~V}$ ) was implemented to prepare thin foil samples for TEM observation (JEM 2100 made by JEOL, Tokyo, Japan). X-ray diffraction was employed on the samples for phase identification with $\mathrm{CuK} \alpha$ radiation.

\section{Results and Discussion}

\subsection{Initial Microstructure and Stacking Fault Energy of the Steel}

The initial microstructure of the steel after solution treated at $1100^{\circ} \mathrm{C}$ for $1 \mathrm{~h}$ followed by quenching is shown in Figure 1a. The annealing twins consisted in most grains and run through the entire austenite grain. The whole austenite's grain size was $45 \mu \mathrm{m}$. The XRD analysis (Figure 1b) revealed that the steel was fully austenitic in which the integrated intensities of the peaks of $\gamma(111), \gamma(200), \gamma$ (220), $\gamma$ (311) and $\gamma$ (222) are regarded as austenite. 

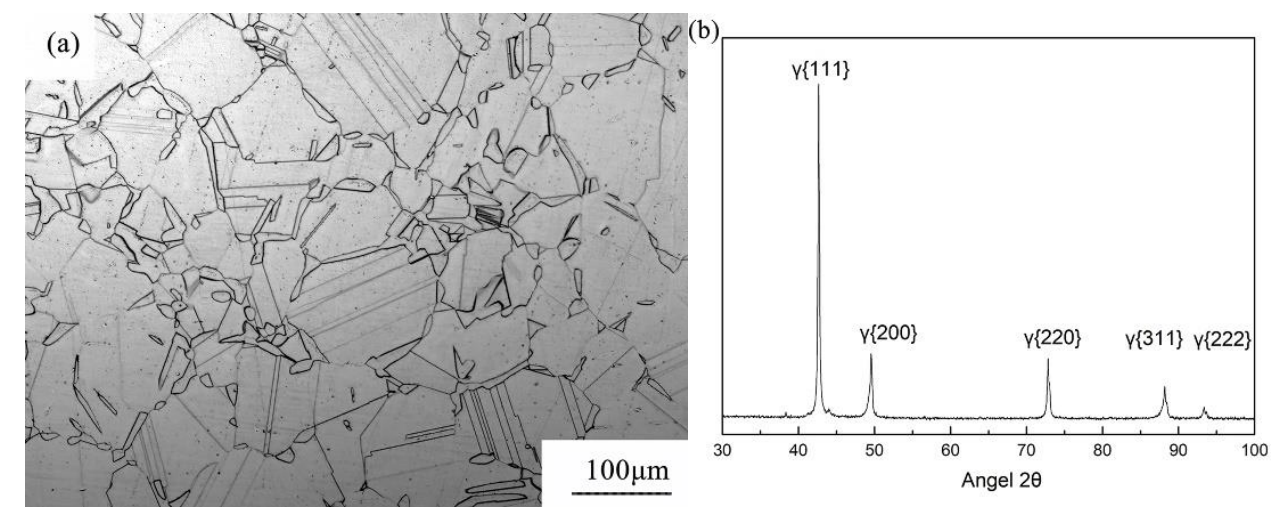

Figure 1. (a) Initial OM microphotograph of the steel; (b) XRD spectra of steel.

SFE is an important parameter to study the correlation between microstructure and tensile behavior of the high-Mn Fe-Mn-Al-C steels. The most effective way to improve SFE is to increase the content of Al element in high-Mn steel [6]. The $\gamma_{S F E}$ can be estimated by [9]:

$$
\begin{gathered}
\gamma_{S F E}=2 \rho_{A} \Delta G^{\gamma \rightarrow \varepsilon}+2 \sigma^{\gamma \rightarrow \varepsilon}, \\
\rho=\left(\frac{4}{\sqrt{3}}\right)\left(\frac{1}{\alpha^{2} N_{A}}\right) .
\end{gathered}
$$

where $\rho_{A}$ is the molar planar density of $\{111\}$ planes, $\sigma$ is the interfacial energy of $\gamma / \varepsilon$, and $N$ is the Avogadro number.

$$
\begin{aligned}
\Delta G^{\gamma \rightarrow \varepsilon}=X_{F e} \Delta G_{F e}^{\gamma \rightarrow \varepsilon}+X_{M n} \Delta G_{M n}^{\gamma \rightarrow \varepsilon}+X_{A l} \Delta G_{A l}^{\gamma \rightarrow \varepsilon}+X_{C} \Delta G_{C}^{\gamma \rightarrow \varepsilon}+X_{F e} X_{M n} \Omega_{F e M n}^{\gamma \rightarrow \varepsilon} \\
+X_{F e} X_{A l} \Omega_{F e A l}^{\gamma \rightarrow \varepsilon}+X_{F e} X_{C} \Omega_{F e C}^{\gamma \rightarrow \varepsilon}+X_{M n} X_{C} \Omega_{M n C}^{\gamma \rightarrow \varepsilon}+\Delta G_{m g}^{\gamma \rightarrow \varepsilon}
\end{aligned}
$$

where $X$ is the atomic molar fraction, $\Omega$ is the excessive mixing energy and $\Delta G$ is the Gibbs energy for the magnetic state of the phase.

$$
\begin{gathered}
\Delta G_{m g}^{\gamma \rightarrow \varepsilon}=G_{m \sigma}^{\varepsilon}-G_{m \sigma^{\prime}}^{\gamma} \\
G_{m g}^{\varphi}=R T \ln \beta^{\varphi}+1 f\left(\mathrm{~T} / T_{\text {Neel }}\right) .
\end{gathered}
$$

$T_{\text {Neel }}$ is the Neel temperature, $\beta$ is the magnetic moment depending on the composition.

When $\tau=T / \mathrm{T}_{\mathrm{Neel}}<1$,

$$
\mathrm{f}(\tau)=1-\frac{\left(79 \tau_{\varphi}^{-1} / 140 P\right)+(474 / 497)[(1 / P)-1]\left[\left(\tau_{\varphi}^{3} / 6\right)+\left(\tau_{\varphi}^{6} / 135\right)+\left(\tau_{\varphi}^{15} / 600\right)\right]}{D}
$$

When $\tau=T / \mathrm{T}_{\text {Neel }}>1$,

$$
f(\tau)=-\frac{\tau_{\varphi}^{-5} / 10+\tau_{\varphi}^{-15} / 315+\left(\tau_{\varphi}^{-25} / 1500\right)}{D} .
$$

Where $\mathrm{P}=0.28, \mathrm{D}=2.34$.

The $\gamma_{S F E}$ and $\Delta G^{\gamma \rightarrow \varepsilon}$ of the present Fe-22.8Mn-8.48Al-0.86C steel were calculated as $71.5 \mathrm{~mJ} / \mathrm{m}^{2}$ and $910.1 \mathrm{~J} / \mathrm{mol}$ at room temperature from equations. Table 2 lists the parameters used in the calculation. 
Table 2. The parameters used in the calculation of the SFE.

\begin{tabular}{|c|c|}
\hline Parameters & Value and Functions \\
\hline$\rho_{A}$ & $2.94 \times 10^{-5}\left(\mathrm{~mol} / \mathrm{m}^{2}\right)$ \\
\hline$\sigma^{\gamma \rightarrow \varepsilon}$ & $9\left(\mathrm{~mJ} / \mathrm{m}^{2}\right)$ \\
\hline$\Delta G_{F \rho}^{\gamma \rightarrow \varepsilon}$ & $-2243.38+4.309 \mathrm{~T}(\mathrm{~J} / \mathrm{mol})$ \\
\hline$\Delta G_{\Delta \eta}^{f, e}$ & $-1000+1.123 \mathrm{~T}(\mathrm{~J} / \mathrm{mol})$ \\
\hline$\Delta G_{A l}^{M, \eta}$ & $2800+5 \mathrm{~T}(\mathrm{~J} / \mathrm{mol})$ \\
\hline$\Delta G_{C}^{\beta \rightarrow \varepsilon}$ & $-22,166(\mathrm{~J} / \mathrm{mol})$ \\
\hline$\Omega_{F e M n}^{\gamma \hookrightarrow \varepsilon}$ & $2180+532\left(X_{F e}-X_{M n}\right)(\mathrm{J} / \mathrm{mol})$ \\
\hline$\Omega_{F e A l}^{\gamma \rightarrow \varepsilon}$ & $3339(\mathrm{~J} / \mathrm{mol})$ \\
\hline$\Omega_{F e C}^{f y e c}$ & $42,500(\mathrm{~J} / \mathrm{mol})$ \\
\hline$\Omega_{M n c}^{r l f \in \varepsilon}$ & $26,910(\mathrm{~J} / \mathrm{mol})$ \\
\hline$\beta^{\gamma}$ & $0.7 X_{F e}+0.62 X_{M n}-0.64 X_{F e} X_{M n}-4 X_{C}$ \\
\hline$\beta^{\varepsilon}$ & $0.62 X_{M n}-4 X_{C}$ \\
\hline$T_{\text {Nee }}^{\gamma}$ & $250 \ln \left(X_{M n}\right)-475 X_{M n} X_{C}-6.2 \mathrm{Al}+720(\mathrm{~K})$ \\
\hline$T_{\text {Nee; }}^{\varepsilon}$ & $58 X_{M n}(\mathrm{~K})$ \\
\hline
\end{tabular}

\subsection{Mechanical Properties}

Figure 2a shows the engineering stress-strain curve of experimental steel at room temperature. The steel exhibited continuous yielding and extensive strain hardening. Excellent mechanical properties, combining high strength (tensile strength of $757.43 \mathrm{MPa}$ ) and ductility (elongation to failure of $68 \%$ ). The product of tensile strength and total elongation is $51.5 \mathrm{GPa} \%$. The emergence of a large number of twins makes the experimental steel with a high degree of plasticity still maintain a certain intensity. The true stress-strain curve of the steel is presented in Figure $2 b$ with the corresponding strain hardening rate $(d \sigma / \mathrm{d} \varepsilon)$. Strain hardening was not linear but continuous. Analysis of the work hardening behavior of experimental steel shows that the $d \sigma / \mathrm{d} \varepsilon$ curve can be subdivided into three stages: the first stage with a rapid reduction in work hardening rate until the strain of 0.06128 ; the continuous hardening state with a constant work hardening rate of $1691 \mathrm{MPa}$; the last stage with a work hardening rate that declines until failure occurs.
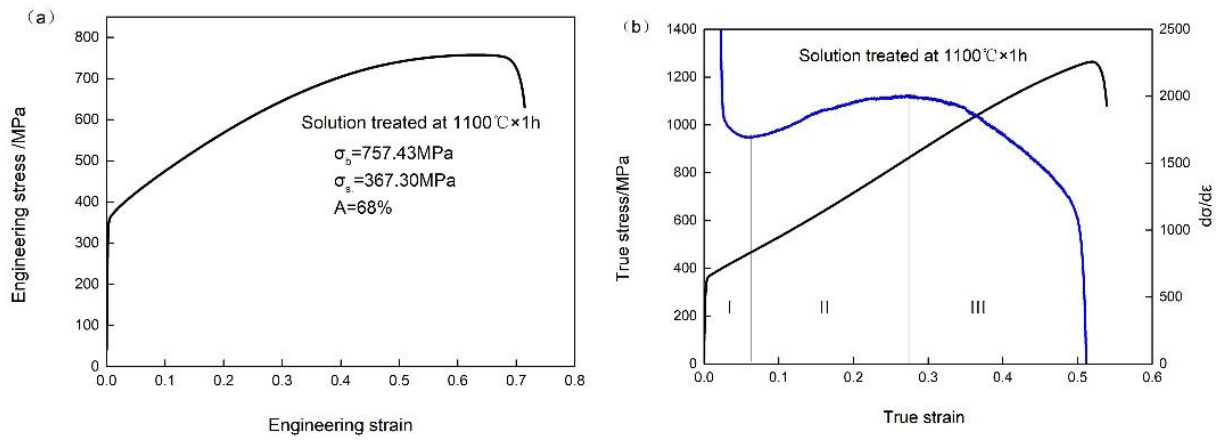

Figure 2. (a) The stress-strain curve of experimental steel; (b) the true stress-strain curve and work hardening curve of experimental steel.

\subsection{Deformation Structure with Increasing Strain}

Figure 3a-c show the SEM micrographs of the steel deformed to the different strain levels. Due to the high content of alloying elements and the stacking fault energy, the austenite in the tensile deformation at room temperature showed a large number of slip bands, and as the strain increased, the amount of slip bands increased and formed cross-slip slip in different directions. 

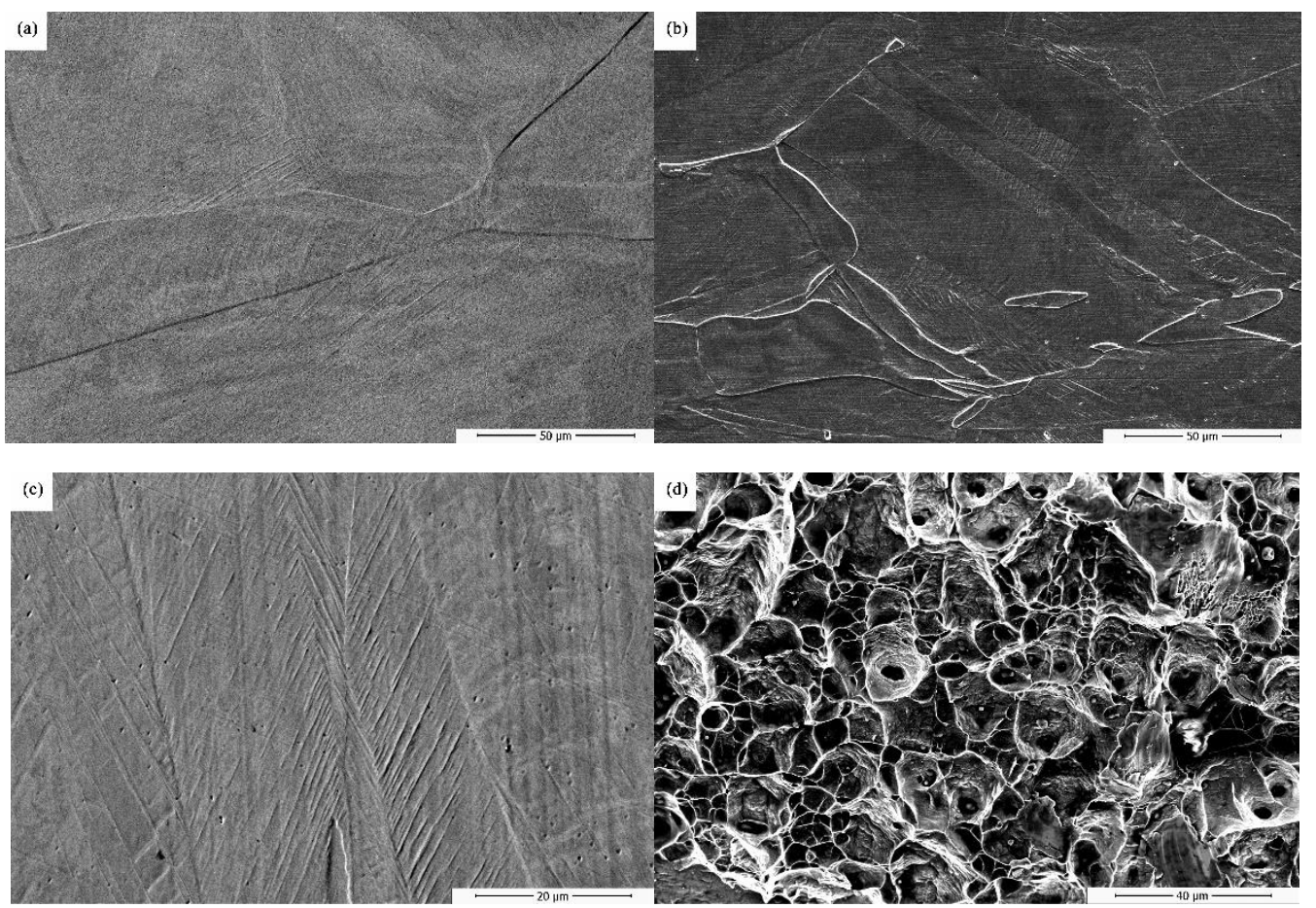

Figure 3. Micrographs of steel at different strain. (a) $0 \%$; (b) 30\%; (c) after failure at 68\%; (d) tensile fracture.

At $10 \%$ strain, only elastic deformation occurred without obvious change of sample, but a small amount of parallel slip bands appeared on the austenite matrix, and stretched slightly along the tensile direction. At $30 \%$ strain, the density of slip band increased obviously. Piles of slip bands continuously passed through the twin boundaries with internal deflection while maintaining the same extending direction. Some of the twins ruptured under the action of slip line, and the grains were bent along the direction of stretching. The phenomenon is due to the exactly same grain orientation and slip direction on the two sides of annealing twin boundaries. At the same time, a small amount of cross-slip bands started to appear among the grains. At $68 \%$ elongation, a large number of slip bands could be observed in the grains, symmetrical slip bands were observed on both sides of the twin boundaries, and the slip bands bent under the strain.

Samples were taken near the tensile fracture to observe. The tensile fracture was shown in Figure $3 \mathrm{~d}$, the fracture surface by the well-developed dimples. In the tensile fracture morphology small equiaxed dimples contained larger dimples in which the spiral stripes could be observed. This is the slip streak produced by the inner surface of the cavity when the dimple grew gradually. The pattern formed when the material fractured along the slip surface. Fracture morphology of the steel is a dimple pattern with features of plastic fracture.

It is known from the relationship between the rate of work hardening and the true strain that the characteristics of the microstructures are different in the three stages of the deformation, and the plastic deformation mechanism of steel is also different. As the amount of deformation increases, the experimental work-hardening mechanism of the test steel during the tensile deformation gradually changed from dislocation reinforcing to microbands reinforcing.

Metal working hardening is mainly caused by the dislocation slip behavior, and the disruption of dislocation slip is firstly the effect of the solution atom. A large amount of solid solution atoms in the test steel made the crystal lattice distortion, and the interaction between dislocations and solid solution atoms increased sharply, blocking dislocation slip strongly. Under stress, a slew of dislocations in the steel soon hindered, and the trend of hardening and work hardening curve was the same. The diffraction pattern (Figure $4 a$ ) confirms the existence of $k$ carbide which precipitated in austenite 
during water quenching. The $\mathrm{k}$ carbide was a spinodally decomposed product corresponding to the carbon-rich regions in austenite. The $\mathrm{k}$-carbides have been universally observed in Fe-Mn-(6-11 $w \mathrm{t} \%) \mathrm{Al}-(0.5-1.8 \mathrm{wt} \%) \mathrm{C}$ steels contents [10-12]. Dislocation-particle pinning event was not observed in detailed TEM observations. It indicates that the blocking effect of nanoscale k-carbide on dislocation motion is weak since the carbide is dislocated in the process of plastic deformation by dislocation carbide without shear dislocation entanglement [13]. The dislocation tangle and slip surface softening caused the increase and decrease of work hardening rate respectively.
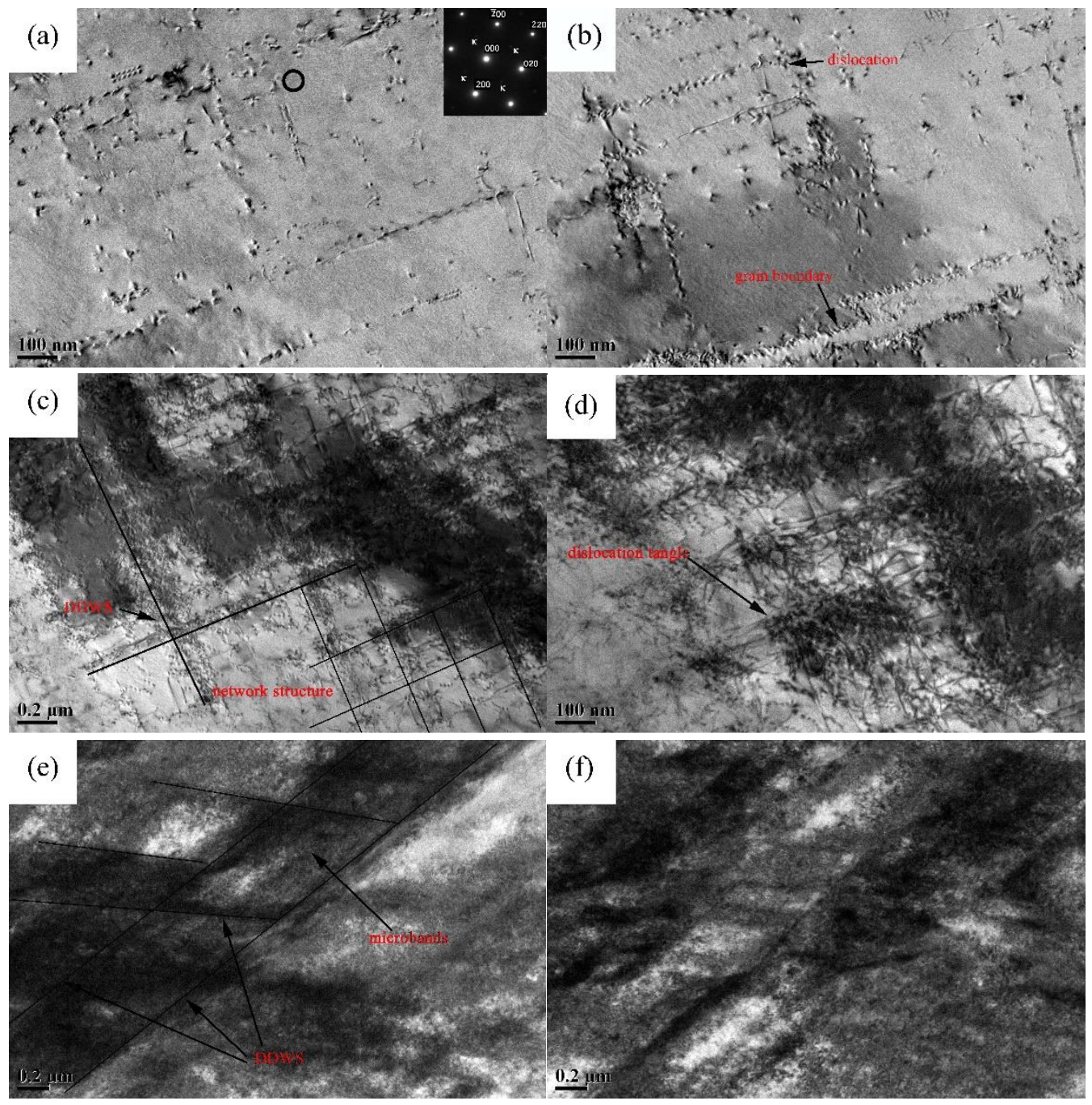

Figure 4. TEM micrographs showing the microstructure of steel at different strain; (a), (b) 10\%; (c), (d) $30 \% ;(\mathbf{e})$, (f) after failure at $68 \%$.

In the second stage of deformation, Figure $4 \mathrm{c}$, d show that dislocations were generated continuously as the deformation increased, single or multiple dislocations distributed or plugged at the grain boundaries continuously, and a large number of tangled dislocations caused stress concentration. The higher SFE of the steel inhibited the generation of deformation twins; these dislocation groups contain different average dislocation densities, indicating that the plastic deformation was in the direction of the main glide system. When secondary slides started, dislocation in different directions crossed and formed network structure. A number of dense density dislocation walls parallel to each other can be observed with an average distance of about $100 \mathrm{~nm}$. This increasingly hindered dislocation movement and decreased the distance that the dislocations can slide freely, resulting in a local hardening rate improvement [14-16]. 
In the third stage of deformation, the maximum deformation at room temperature was $68 \%$. The hardening rate decreased with increasing strain, and as the strain increased continuously, new slip lines did not appear between the slip bands any more. In the final stage of dislocation slip, two parallel dislocations walls containing a large amount of geometrically dislocations formed microbands. The dislocation density in the microbands is higher, but the activity ability is poor. The deformation is concentrated in the original slip band, and microbands delivery in different directions produced a structure similar to the cystiform microstructure as shown in Figure 4 Austenite grains were subdivided, and the effective free path of dislocation motion was shortened. This leads to a slight increase (compared with the second stage) in the work hardening effect of the material.

\section{Conclusions}

1. Fe-22.8Mn-8.48Al-0.86C steel after solid treatment at $1100{ }^{\circ} \mathrm{C}$ for $1 \mathrm{~h}$ was austenitic with annealing twins through the austenite grain. The experimental steel possesses excellent comprehensive mechanical properties, with a high strength of $757.43 \mathrm{MPa}$ and an elongation of $68 \%$. With the increase of strain, the working hardening rate is on the rise uninterruptedly during tensile deformation before plastic collapse;

2. $\gamma_{S F E}$ and $\Delta G^{\gamma \rightarrow \varepsilon}$ of the present Fe-22.8Mn-8.48Al-0.86C steel at room temperature were estimated as $71.5 \mathrm{~mJ} / \mathrm{m}^{2}$ and $910.1 \mathrm{~J} / \mathrm{mol}$. During the tensile deformation, amounts of slip parallel bands formed on austenite matrix. The density of the slip bands increased, and then slip bands in different directions crossed with the increase of strain.

3. The steel shows characteristics of typical glide during the deformation. Dislocation multiplied at low deformation, dislocations tangled and dense dislocation walls formed at middle deformation. As the deformation increased, microbands formed and intersected. The work-hardening mechanism of the test steel changed gradually from dislocation reinforcing to microbands reinforcing.

Author Contributions: Conceptualization, Z.Z. (Zhanming Zhou) and Z.Z. (Zhengzhi Zhao); methodology, J.P. and D.T.; validation, J.P., Z.Z. (Zhanming Zhou) and Q.H.; formal analysis, J.L., Z.Z. (Zhengzhi Zhao) and J.P.; writing-original draft preparation, J.P.; writing—review and editing, J.L. and Z.M.Z; supervision, D.T.; project administration, Z.Z. (Zhengzhi Zhao)

Funding: Zhengzhi Zhao acknowledges the financial supports by the National Key Research and Development Program of China (Project No. 2017YFB0304400) and the National Nature Science Foundation of China (No.51574028).

Conflicts of Interest: The authors declare no conflict of interest.

\section{References}

1. Tang, D.; Mi, Z.-L.; Chen, Y.-L. Technology and research and development of advanced automobile steel abroad. J. Iron. Steel 2005, 40, 1-5.

2. Cai, Z.H.; Ding, H.; Misra, R.D.K.; Kong, H.; Wu, H.Y. Unique impact of ferrite in influencing austenite stability and deformation behavior in a hot-rolled Fe-Mn-Al-C steel. Mater. Sci. Eng., A. 2014, 595, 86-91. [CrossRef]

3. Kim, H.; Suh, D.W.; Kim, N.J. Fe-Al-Mn-C lightweight structural alloys: a review on the microstructures and mechanical properties. Sci. Technol. Adv. Mater. 2013, 14, 014205. [CrossRef] [PubMed]

4. Yoo, J.D.; Park, K.T. Microband-induced plasticity in a high Mn-Al-C light. Mater. Sci. Eng., A. 2008, 496, 417-424. [CrossRef]

5. Chen, S.; Rana, R.; Haldar, A.; Ranjit, K.R. Current state of Fe-Mn-Al-C low density steels. Prog. Mater. Sci. 2017, 89, 345-391. [CrossRef]

6. Allain, S.; Chateau, J.P.; Bouaziz, O.; Migot, S.; Gueton, N. Correlations between the calculated stacking fault energy and the plasticity mechanisms in Fe-Mn-C alloys. Mater. Sci. Eng., A. 2004, 387, 158-162. [CrossRef]

7. Park, K.T.; Kim, G.; Kim, S.K.; Lee, S.W.; Hwang, S.W.; Lee, C.S. On the transitions of deformation modes of fully austenitic steels at room temperature. Met. Mater. Int. 2010, 16, 1-6. [CrossRef] 
8. Canadinc, D.; Sehitoglu, H.; Maier, H.J.; Chumlyakov, Y.I. Strain hardening behavior of aluminum alloyed Hadfield steel single crystals. Acta Mater. 2005, 53, 1831-1842. [CrossRef]

9. Hirth, J.P. Thermodynamics of stacking faults. Metall. Trans. 1970, 1, 2367.

10. Choi, K.; Seo, C.H.; Lee, H.; Kim, S.K.; Kwak, J.H.; Chin, K.G.; Park, K.T.; Kim, N.J. Effect of aging on the microstructure and deformation behavior of austenite base lightweight Fe-28Mn-9Al-0.8C steel. Scr. Mater. 2010, 63, 1028-1031. [CrossRef]

11. Chang, K.M.; Chao, C.G.; Liu, T.F. Excellent combination of strength and ductility in an Fe-9Al-28Mn-1.8C alloy. Scr. Mater. 2010, 63, 162-165. [CrossRef]

12. Kimura, Y.; Handa, K.; Hayashi, K.; Mishima, Y. Microstructure control and ductility improvement of the two-phase $\gamma$-Fe/k-(Fe, Mn) 3 AlC alloys in the Fe-Mn-Al-C quaternary system. Intermetallics 2004, 12, 607-617. [CrossRef]

13. Gutierrez-Urrutia, I.; Raabe, D. Influence of Al content and precipitation state on the mechanical behavior of austenitic high-Mn low-density steels. Scr. Mater. 2013, 68, 343-347. [CrossRef]

14. Park, K.T. Tensile deformation of low-density Fe-Mn-Al-C austenitic steels at ambient temperature. Scr. Mater. 2013, 68, 375-379. [CrossRef]

15. Hughes, D.A. Microstructural evolution in a non-cell forming metal: Al-Mg. Acta Metall. Mater. 1993, 41, 1421-1430. [CrossRef]

16. Yang, F.; Song, R.; Li, Y.; Sun, T.; Wang, K.K. Tensile deformation of low density duplex Fe-Mn-Al-C steel. Mater. Des. 2015, 76, 32-39. [CrossRef]

(C) 2019 by the authors. Licensee MDPI, Basel, Switzerland. This article is an open access article distributed under the terms and conditions of the Creative Commons Attribution (CC BY) license (http://creativecommons.org/licenses/by/4.0/). 